\title{
ON THE APPARENT PERSISTENCE OF DISPARLURE IN THE HUMAN BODY
}

\author{
E. ALAN CAMERON \\ Deparment of Entomology \\ Pemin State University \\ University Park. Pennivilania /6802
}

(Received November 18, 1994: accepted December 1, 1994)

Key Words-Gypsy moth: disparlure, Lymamria dispar

Previously I reported on long-term persistence of personal attractiveness to the gypsy moth, Lymantria dispar (L.) (Lepidoptera: Lymantriidae) following my exposure to the racemic form of its attractant, disparlure (cis-7-8-epoxy-2-methyloctadecane) (Cameron, 1981, 1983). My last known direct contact with disparlure was during the 1977 field season.

For the historical record, I note the following facts. Even though rigorous testing, such as that reported in my 1983 paper, has not been repeated, I have noted during each succeeding field season whether or not attractiveness persisted. Each field season through and including the summer of 1993, male gypsy moths continued to orient to and commonly make contact with me under a variety of conditions; no plausible explanation other than my persisting personal attractiveness to these insects could explain the phenomenon. For example, during casual conversations with colleagues while we were standing in paved parking lots at least tens of meters from the nearest tree, we have observed male moths exhibiting typical response behavior oriented towards my legs and torso but not to other individuals. Subjectively, I suspect a modest diminution of my attractiveness in recent years, but this may only reflect changes in naturally occurring populations.

During the summer of 1994, I participated in trapping tests during which I baited numbers of gypsy moth traps with synthetic lures. Although I took rigorous precautions to avoid direct contact with any of the lures, doubtless at a minimum I inhaled at least small quantities of pheromone. My original "contamination" was through an undetermined route(s), but certainly inhalation would 
not be excluded. I believe that it reasonably can be argued that my personal "experiment" must be concluded. A few early-season observations in 1994, before my first possible exposure to any disparlure, strongly suggested that I retained attractiveness for 17 years following my last previous known exposure. At a minimum, the period of attractiveness was 16 years, or through the 1993 field season.

\section{REFERENCES}

CAmeron. E.A. 1981. On the persistence of disparlure in the human body. J. Chem. Ecol. 7: 313317.

CAmFron, E.A. 1983. Apparent Iong-term hodily contamination by disparlure, the gypsy moth (Lymumiria dispar) attractant. J. Chem. Ecol, 9:33-37. 